\title{
CAMBIOS EN LA ESTRUCTURA SOCIAL DEL MEZZOGIORNO
}

\author{
Gabriella Pinnard \\ Enrico Pugliese \\ (Università di Salerno)
}

En este trabajo sobre los cambios en la estructura social en la Italia meridional se tratan tres categorías de problemas. La primera es relativa a la evolución del bloque social dominante y de su estructura interna; la segunda, a la evolución de la relación ciudad-campo en el Sur y el papel que desempeña la realidad urbana en relación a los procesos de industrialización del territorio y de intervención del sector público en la economía meridional; la tercera, en cambio, se refiere sobre todo a la composición de las clases subalternas tomando en cuenta el origen y los aspectos de la estructura socioprofesional, fundamentalmente en lo concerniente a los estratos que se pueden agregar al bloque dominante, y en particular sectores de la pequeña burguesía. Se trata de tres aspectos estrechamente interrelacionados. La nueva telación cirudad-campo se expresa también en la progresiva concentración del poder económico y político en la ciudad, en que las clases - -0 , para ser más precisos, las fracciones de clase- que constituyen el bloque dominante son esencialmente urbanas, y en que la nueva estructura socioprofesional asiste a la consolidación de figuras sociales típicamente urbanas, con el drástico redimensionamiento de figuras sociales ligadas a la agricultura. 
La nueva función del Mezzogionno en el desarrollo económico del país, la progresiva disminución de la importancia relativa de la agricultura -incluso en la propia economía meridional-, sus colosales desplazamientos de población (no sólo hacia otras tegiones, sino también en su interior, del campo a la ciudad) han creado una estructura social y una estructura ocupacional radicalmente diferente de la que había hace treinta años, inmediatamente antes de la intervención de la Reforma de la Propiedad Agrícola y de la institución de la Caja para el Mezzogiono. La modificación del papel económico del Mezzogiorno, que a partir de su condición de área de drenaje de capitales y de fuerza de trabajo tiende a convertitse en área hacia donde también se dirige una porción importante del gasto público, se refleja -a nivel de Ias clases sociales- en que la clase dirigente meridional basa su función de liderazgo directamente en la intervención estatai; la mediación política, como fuente de poder, comienza a asumir una función central y determinante. En la estructura social actual, tras treinta años de política de intervención con un Estado «inversor» y «transferidor de tecursos», se advierte en la jerarquía social un claro privilegio de las capas ligadas al sector público. Y la redistribución del poder pone en la cúspide de la pirámide meridional una capa pública urbana. ${ }^{1}$

Para comprender estos procesos, tanto los telativos a la constitución del bloque social dominante como los concernientes a la modificación de la estructura socioprofesional y a su articulación territotial, hay que tener siempre presente un esquema unitario de interpretación que tenga en cuenta no sólo la existencia y el peso numérico de las diferentes clases sociales, sino que permita también, y sobre todo, comprender la formación y/o la

1. Acerca đel nuevo papel deł Estado para el Mezzogiorno, véase A. Graziani, «El Mezzogiono nell'economia italiarla oggi», Inchiesta, núm. 27; y con mayor razón A. Gioannola y A. Del Monte, Il Mezzogiorno nello sviluppo economico italiano (BoIonia: Yl Mulino, 1978). 
expansión de un estrato determinado y en particular las relaciones entre las diversas clases.

En este trabajo, aun tomando en consideración las indicaciones que proporciona el actual estado de la discusión sobre las clases en Italia, ${ }^{2}$ se ha escogido el marxista como esquema referencial de interpretación. Este esquema no sólo permite analizar la constitución y la definición de las clases y de las categorías conexas a la luz del cambio -por tanto, de un factor dinámico-, sino también distinguir los elementos básicos de una determinada estructura social y los mecanismos del desarrollo económico. Se trata de un esquema dicotómico que distingue, por una parte, los posesores de los medios de producción - y en una economía cada vez más caracterizada por la incidencia de la intervención pública de quienes, aun sin ser necesariamente propietatios, controlan los medios de produccion- $-y$, por otra parte, los poseedores de la fuerza de trabajo. Este esquema analítico no implica la ausencia de ottos estratos, sino que al distinguit dos clases como centrales considera la emergencia y la consolidación de eventuales estratos intermedios como resultado de la evolución de sus relaciones. Además, hablar de dos clases fundamentales no significa suponer también que sean internamente homogéneas. La burguesía no sólo se muestra compuesta, sino que, en las diversas fases del desarrollo histórico de un determinado sistema social, predomina en su seno ya un estrato, ya otro, de donde la necesidad de distinguir el bloque dominante mediante el análisis de su composición y de sus medios de control y/o de la agregación de los estratos subalternos. Naturalmente, para el análisis de las clases subalternas, también es necesaria la referencia al modelo de desarrollo. Así, el éxodo más o menos acelerado de los campesinos, lo mismo que su proletarización, la persistencia y la crisis acelerada de los estratos artesanales, la consolidación más o menos significativa de los estratos terciarios improductivos, son todos resultados del carácter que adopta el proceso de acumulación, y en relación a éste han de analizarse. En efecto, tal como ha sucedido en Italia, un acelerado proceso de desarrollo capitalista sacude las estructuras productivas tradicionales y libera fuerza de trabajo, es decir, expulsa a los trabajadores que en él se ven envueltos. ¿Cómo es esta fuerza de trabajo «liberada», este

2. Hoy se cuenta ya con una larga documentación de fácil consulta acerca de todo cuanto se ha producido en materia de análisis de las clases sociales en nuestro país gracias a las antologías de M. Paci, Sviluppo capitalistico e classi sociali (Bolonia: Ii Mulino, 1978), de G. Ragone y C. Scrocca, La Sociologia delle classi socidli in Italia (Liguoti, 1978). Para una documentación de la discusión acerca de las clases sociales en Italia y ulteriores informactones bibliograficas, véase $G$. Pinnat $\partial$, the classi sociali in Italia: note su un dibattiton, en Queste istituzioni, 14 (1977). 
conjunto de estratos que se han vuelto proletarios, y en qué medida la reabsorbe el proceso productivo? La respuesta se hallará en el análisis de las estructuras productivas y en particular en la del sector industrial.

En lo que se refiere a nuestro país, a una notable liberación de fuerza de trabajo de los sectores tradicionales y a una escasa capacidad de absorción por parte de la industria, ha correspondido un fuerte aumento de estratos que terminan por no estar insertos en el proceso productivo $-\mathrm{y}$ que se convierten en población «subsidiada»-y que en general son absorbidos por la actividad burocrática y la actividad de servicios. Muy a menudo este dato ha permanecido en la confusión y ha llevado a sacar conclusiones acerca de un fuerte incremento de la capa media. Veremos más adelante cuán discutible y cuán importante es analizar en términos correctos la consistencia y la situación de clase de los nuevos estratos pequefro-burgueses, incluso en relación con la incidencia que tienen en la peculiar configuración de la realidad territorial del Mezzogiomo y en particular de la organización política y socioeconómica de la ciudad metidional.

\section{Evolución del bloque social dominante y de su estructura interna}

En lo que se teffere al primer punto de nuestro trabajo, esto es, el análisis de la evolución del bloque social dominante y de su estructura interna, aun en relación a la realidad meridional, vale la pena tener en cuenta los nexos nacionales del problema. En efecto, se puede observar que en el sistema de clase italiano siempre hubo un componente meridional en el bloque dominante, componente que tuvo un papel y una gravitación muy importante como clase dirigente en escala nacional, $y$, por otra parte, que la composición y la connotación de la clase ditigente del Mezzogionno varía en relación a la estructura económica no sólo interna del Sur, sino también de la nacional.

Mientras la economía del Mezzogiarno fue esencialmente agrícola, la clase dominante no podía dejar de estar ligada a la agricultura. En efecto, la tierra era la base del poder político y económico. Las cosas se modifican cuando el Mezzogionno deja de ser una simple área de drenaje de recursos para convertirse, en los tiempos más tecientes, en área de absorción de un flujo de recursos, ya como flujo de inversiones, ya como flujo de gasto público bajo la forma de sueldos, pensiones, etc. Esta profunda modificación de la función económica corresponde a una modificación igualmente importante en la estructura de la clase dirigente, que en un comienzo estaba representada por la burguesía terrateniente ligada a la renta y ahora lo está por la burguesía de Estado. 
En lo que respecta a la primera fase, el análisis más profundo del bloque social dominante en nuestro país es el que realizó Gramsci, quien interpretó este bloque como la unión de los intereses de la burguesía tertateniente meridional y la burguesía industrial monopolista del Norte. Este análisis, que aparece sobre todo en los escritos de Il Risorgimento y de La Questione Meridionale, ${ }^{3}$ también se encuentra en las tesis de Lione del PCI, subraya el carácter inconcluso de la revolución del Risorgimento y ve en el compromiso entre estratos capitalistas emergentes y estratos de la gran burguesía o de la aristocracia ligados a la renta del suelo, la raíz de la formación del bloque dominante. Como se sabe, Gramsci contrapone a este bloque, responsable del subdesarrollo del Mezzogiomo y del carácter «andrajoso» propio del capitalismo italiano, la posibilidad de la formación de un bloque social antagonista constituido por los obreros de las regiones del Norte y por los campesinos del Sur. Por lo tanto, esquemáticamente, en este marco los principales actores sociales son, en la burguesía, su componente agraria y su componente industrial, y en las clases subaiternas, los campesinos -entendidos como «campesinos pobres»- y los obteros. En el Mezzogiorno la antinomia histórica de clases es la que se da entre «baroni" * y "campesinos».

Sin profundizar en los detalles de este análisis, es conveniente, con todo, estudiar de qué modo entró en crisis ese biogue social que Gramsci definieza, es decir, de qué modo la burguesía terrateniente meridional fue perdiendo funcionalidad, de qué modo se produjo su liquidación como clase en el poder a escala nacional y cómo la gran burguesía de Estado fue desplazándola hasta sustituirla por completo.

El análisis del desartollo capitalista italiano predominante hasta ahora, concibió el período fascista como el período de consolidación de las tradicionales alianzas de clase dentro de la burguesía. Es decir, que en el predominio del capital monopolista y financiero se vio el cumplimiento de un proceso que se iniciara con la Unidad y se consolidara en 1887 con

3. A. Gramsci, Il Risorgimento (Roma: Ed. Riuniti, 1971) y La questione meridionale, a cargo de V. Parlato y F. De Felice (Roma: Ed. Riuniti). Es fundamental, aunque presente un aspecto esquemático, el trabajo que con especial referencia a los aspectos estructurales se debe a $\mathrm{E}$. Sereni, La questrone agraria nella rinascita nazionale (Einaudi, 1947) y sobre todo el ensayo «Il modo della politica granatia», en Capitalis. mo e mercato nazionale (Roma; Ed. Riuniti, 1966).

* Baroni: Señores poderosos, patronos, personas de gran poder económico.

4. Nos parece que esta interpretación queda clara tanto en el ya citado texto de Seteni La questione agraria nella rinascita nazionale, como en el importantísimo estudio de $P$. Grifone, $I l$ capitale monopolistico in Italia (Einaudi, 1971) con introducción de V. Foa. 
el comienzo del proteccionismo, de la misma manera que en las medidas atutárquicas y en particular en la batalla del grano se vio la prosecución de la protección incondicional que se había acordado a los productos agrarios. No cabe duda, por cierto, de que el fascismo garantizara notables privilegios a la burguesía terrateniente, al menos en lo que concierne a su capacidad de opresión económica y social sobre las capas rurales subalternas. Pero la historiografía más reciente ha puesto en claro algunos elementos de particular importancia para la comprensión de este período y en particular ha hecho evidentes los gérmenes de disolución del bloque por iniciativa de la burguesía capitalista y la búsqueda, por parte de esta última, de una partnersbip de otro tipo. ${ }^{5}$

La reestructuración capitalista que tuvo lugar durante el fascismo produjo una modificación de la estructura del Estado y una compenetración entre poder capitalista y poder estatal. Durante el fascismo se produce en economía un nuevo tipo de intervención del Estado, directa y masiva. Entonces el Estado asume un nuevo papel como empresario e incluso como regulador activo del proceso económico. La acción de salvamento de las empresas, el establecimiento del IRI, no representan tanto un recurso para «privatizar los beneficios y socializar las pérdidas» -como la propia izquierda lo entendió a menudo-, sino como una compleja opción de desarrollo del sistema económico italiano y en particular de la industria. Por lo demás, esa acción corresponde a una asignación de recursos favorable a la industria monopolista destinada a ser pagada por todas las capas agrícolas, incluidas las de propietarios.

En este matco de política económica es donde hace su aparición esta nueva "clase»: la burguesía de Estado. Su composición y su misma función -que más adelante analizaremos detalladamente- son particularmente complejas debido a la multiplicidad de las funciones que desempeñan sus componentes y a la diversa situación de clase que a éstos corresponde. Durante el fascismo consolida y articula su presencia, tanto en calidad de funcionaria del aparato industrial-financiero público y semipúblico, como en calidad de conjunto de capas que recubren las diversas funciones del aparato burocrático. Se trata de un proceso que tiene lugar en escala nacional y cuyas implicaciones fundamentales para el Mezzogiorno se aclararán a continuación.

Si bien es cietto que ya dutante el fascismo se hallaban en maduración los elementos de crisis, también es cierto que sólo la violenta temporada de luchas campesinas típica del último período del segundo conflicto mun-

5. Véanse al respecto los capítulos del estudio de V. Castronovo en La Storia d'Italia (Einaudi), volumen IV, tomo I. 
dial y la inmediata posguerra - -luchas que se caracterizaron por el reclamo de la tierra por parte de los campesinos- sacudió definitivamente el bloque definido por Gramsci y obligó al partner hegemónico en la estructura de clase italiana (la burguesía del Norte) a sacrificat los intereses de la burguesía terrateniente con los primeros pasos de reforma de los sectores agrarios con los dectetos de asignación de tierras, y finalmente, en 1950 , con la reforma agraria.

La burguesía terrateniente, a pesar de su liquidación como clase en el poder, encuentra que sus miembros se ven en gran medida compensados de las expropiaciones por la posibilidad de transformarse en capitalistas agrarios - sector de clase ciertamente no golpeado por la Reforma- o bien de transferir su capital a la especulación edilicia urbana, convirtiéndose así en perceptores de renta urbana en vez de perceptores de renta agraria. ${ }^{6}$ Eso tiene lugar en concomitancia con procesos más generales que se refieren a la economía y a la agricultura del Sur, en cuya base encontramos el mismo mecanismo de desarrollo, sutgido del mismo tipo de alianza de clase, mecanismo que se caracteriza, por un lado, por el carácter subalterno de la agricultura y por la incapacidad de extender en el Mezzogiorno la base productiva y ocupacional, y, por otro lado, por garantizar la solidez del bloque dominante a través de las ventajas concedidas a un sector particularmente parasitanio de la burguesía. En la década de 1950 y en los primeros años de la siguiente es cuando la burguesía urbana pasa por su período de mayor potencia, mientras que las ciudades meridionales - como veremos más adelante- sufren un proceso de crecimiento tumultuoso.

Puesto que en este período la especulación edilicia constituye la base del poder económico, los principales exponentes del bloque de poder que gobierna las ciudades mexidionales están ligados a ella, precisamente. Ya no es la tierra la que otorga poder y beneficios a la clase dominante, sino que el poder y la economía se concentran en las áreas urbanas determinando la consolidación de la burguesía terciaria urbana. Es la época de oro para los especuladores de la construcción, que acumulan ingentes fortunas de una manzeta inescrupulosa, «edificando» la ciudad meridional; esta capa, junto con otros estratos, sobre todo los propietarios de tertenos aptos para Ia construcción, es el nuevo protagonista del mapa de poder meridional. Sin embargo, se trata de una fase relativamente breve, pues la crisis de la construcción privada y los cambios que introduce la intervención pública en el Mezzogiorno determinarán, ${ }^{7}$ por una parte, la declinación de la fun.

6. Sobre este tema remitimos al volumen de G. Nottuta y E. Publiese, Agricoltura, Mezzogionno e mercato del lavoro (Bolonia: Il Mulino, 1975).

7. En lo que concierne al papeì del Mezzogiorno como meta de inversiones, véase 
ción de los estratos parasitarios ligados a la renta urbana, y por otra. el surgimiento y el desarrollo de una burguesía definida como «burguesía de Estadon, ${ }^{8}$ ligada - como vetemos mejor más adelante- a la gestión del gasto público y a la industria del Estado. Y el Mezzogionno, en cuanto base económica de la intervención estatal, representa una de las cartas más importantes en el juego de los conflictos y mediaciones en el seno del bloque dominante.

\section{La ciudad meridional y la función de la intervención pública}

Si se tiene presente este cuadro de conjunto se puede intentar analizar el tipo de cambios que habrán de operarse en la estructura utbana meridional de los años cincuenta en adelante. ¿Por qué se desarrolla la ciudad, a qué exigencias responde su crecimiento y, en particular, cuál es el papel que desempeña la realidad urbana meridional cuya especificidad implica diferencias no sólo cuantitativas, sino también cualitativas respecto de la central y la septentrional? Mientras en el Notte lo que atrae a la ciudad grupos de diversa situación social, y en particular proletarios, es el desarrollo industrial, en el Sur esta condición no se cumple, y la continua y creciente presión para abandonar la agricultura que se ejetce sobre las clases subalternas no tiene salida adecuada en el contexto urbano. La fuerza de trabajo que se desplaza del campo a la ciudad no encuentra otro empleo que el precario que puede ofrecerle el sector de la construcción (entre 1951 y 1973, a pesar del descenso del último período, los empleados en este sector pasaron de 359.000 a 724.000) o el parasitario propio del sector terciatio.

En este sentido, la ciudad meridional se erige en el lugar de gestión del excedente de una mano de obra cada vez más disgregada y presenta

el ensayo de A. Collidà en el volumen colectivo Meridionalismo in crisi (Milán: Angeli, 1967). Cierta utilidad presenta el libro de Ferrari Bravo y Serafini, Stato e sottosviluppo (Milán: Feltrinelli, 1972) y también el volumen colectivo a cargo de A. Graziani, Incentivi $e$ investimenti nel Mezzogiono (Milán: Angeli, 1973). Una síntesis de las polfticas de inversión y de sus efectos se halla en el volumen L'economia del Mezzogiorno, a cargo de A. Del Monte y A. Giannola (Bolonia: Il Mulino). A. Pugliese ha Hevado a cabo un análisis de la evolución cuantitativa y cualitativa de las inversiones en el Mezzogiorno, en «Occupazione e investimenti nell'agticoltura meridionale nell'uitimo ventennios, Sviluppo, 44 (1977). Véase también $G$. Amato, $I$ governo dellindustria in Italia (Bolonia: It Mulino, 1972).

8. E. Scalfari-G. Turani, Razza padrona (Milán: Felitinelli, 1974); y G. Galli A. Nannei, Il Capitalismo assistenziale (Sugarco, 1976). Con distinta orientación, A. Mutti - P. Segatti, La borghesio di stato (Milán, 1977). 
todos los problemas de la ciudad capitalista sin participar en ninguna de sus ventajas (niveles de renta, ocupación estable y, desde el punto de vista politico, formación de una clase obrera fuerte). ${ }^{9}$ Aun cuando no parezca correcto hablar de una «tipicidad» de la ciudad metidional, sobre todo si nos referimos a las capitales de provincia, presenta marcados aspectos de anquilosis; la función puede ser agrícola, industrial y de servicio, peto en todo caso la realidad es el predominio de una hipótesis de subsistencia y de congestión sin desarrollo. ${ }^{10}$

Con esto no se pretende decir que en la ciudad meridional no se acumulen actividades - no estamos ante características, por así decir, «africanas»--, sino que se trata generalmente de actividades no productivas, alimentadas por canales de un gasto público administrado en formas clientelares, y es así como la estructura tiene como base el parasitismo y la expansión artificial del sector terciario y de la especulación edilicia. Debido justamente a Ia incapacidad de extender en el Sur la base productiva y ocupacional, se trata de garantizar de algún modo la estabilidad del bloque dominante a través de una gestión política de la disgregación de la masa marginal.

Históricamente la ciudad meridional no se ha caracterizado como asiento de localización industrial (salvo alguna excepción como Napolie Teranto), las zonas «pulpo» no coinciden con ella. Debido a que desarrollo urbano y desarrolio industrial tro se plantean como sinónimos, la transferencia a la ciudad no corresponde a una inserción en actividades productivas; más bien al contrario, el mismo desarrollo ha trastornado por completo las estructuras artesanales tradicionales que no lograron insertarse en el proceso de descentración productiva, como ocurrió en la Italia central $y$ en la septentrional.

Los niveles y la evolución de las tasas de actividad son indicadores útiles del sobredimensionamiento demográfico en la ciudad meridional. En efecto, en Ia media de las ciudades con más de 100.000 habitantes del

9. No hay estudios desarrollados sobre el tema de la ciudad y sería inútil buscat una teoría de conjunto acetca de esto. En los últimos años, sin embargo, es de destacar Ia tendencia a profundizar el análisis debido a la relevancia cada vez mayor que va asumiendo el fenómeno urbano desde el punto de vista no sólo socio-económico, sino también político. En consecuencia, nos parece útil analizar la ciudad como Iugar en donde se reflejan algunos de: los contrastes del sistema capitalista en el sentido en que Ia misma se presenta como momento no secundario en el desarrollo y en la crisis de la sociedad contemporánea.

10. A. Collida, «La città meridionale», Mezzogiorno e crisi, a cargo de F. Indovina Angeli (Milán, 1976), con un trabajo de la misma autora; cf. también Suiluppo economico e crescita urbana in Italia (Mitán: Angeli, 1968). 
Sur, la tasa de actividad extraagrícola es del $25,8 \%$, inferior no sólo a la media de las ciudades septentrionales correspondientes por la dimensión $(35,4 \%)$, sino también inferior a los municipios con menos de 100.000 habitantes que presentan una tasa de actividad del $31,6 \%$.t En particular, Nápoles presenta una dinámica más grave, ya que no sólo la tasa de actividad extraagrícola distrinuye constantemente en los tres censos de población de 1951, 1961 y 1971, sino que en la última década el número absoluto de los activos extraagrícolas está en franca disminución. $Y$ en una ciudad como Teranto, los incorporados a la industria son sólo 9 de cada 100 habitantes. Particularmente en el período 1961-1974, la ocupación total presenta en el Sur una marcha decreciente muy marcada $(10,8 \%$ contra el $6,3 \%$ de la media nacional).

No obstante, el proceso de urbanización de la década de los cincuenta hasta hoy ha sido objeto de grandes aceleraciones. En efecto, en 1951 había 8 ciudades con más de 100.000 habitantes, mientras que en 1971 había 14. Pero el crecimiento cuantitativo no corresponde a modificaciones cuantitativas en la infraestructura de servicios; no hay nada que permita hablar ni siquiera vagamente de «metrópolis del desarrollo con actividades de servicio y funciones de dirección evolucionadas». La realidad es la degradación territorial que pesa sobre toda la sociedad nacional. ${ }^{12}$

Por otra parte, la estructura productiva que, además de hacerlo sobre el sector de servicios y de la administración pública, pesa también sobre la de la construcción, hace extremadamente frágil a la ciudad meridional respecto a las diversas fases de la coyuntura económica y determina en ella características completamente diferentes de las que derivan de los fenómenos de urbanismo en otras regiones del país. Tampoco la relación ciudadcampo se plantea en términos clásicos. No cabe duda de que una relación de dominación se realiza con una concentración del poder en el nivel ciudadano, y de que la base del poder corresponde cada vez más a la gestión de la intervención pública y del aparato estatal precisamente para la ubicación física de los establecimientos institucionales que tienen lugar en la ciudad, y en particular en las grandes ciudades.

11. S. Cafiero, Sviluppo industriale equestione urbane nel Mezzogiorno (Roma: Giuffré, 1976).

12. No aplicable a la realidad de Italia metidional, por tanto es, por ejemplo, el modelo de Czamanski, según el cual «los incrementos en la actividad económica determinan el desarrollo urbano y, en consecuencia, incrementos en la población». Pox eł contrario, nos hallamos ante unas tenazas constituidas por la industrialización-urbanización, y ante la desproporción entre la cuota de población que vive en áreas urbanas y la que tiene en ellas posibilidades de obtener alguna renta. 
Pero comprender esta evolución que se realiza en el plano territorial, esta "expansión urbana sin desarrollo», este carácter de la ciudad que se distingue por la marcada presencia de estratos pequeño-burgueses emplea. dos por el sector terciario, implica una referencia posterior al modelo de desarrollo que ha caracterizado el Mezzogionno. ${ }^{13}$

Naturalmente, es falsa la imagen de un Sur no interesado en los procesos de industrialización. En realidad, hay que distinguit al menos dos fases en el desarrollo económico del Mexzogiorno, que tienen graves implicaciones tanto en el nivel de la articulación territorial del desarrollo, como en el de evolución del bloque social dominante y del papel que desempeña Ia pequeña burguesía.

En una primera fase, que podemos hacer corresponder a la década del cincuenta, la intervención pública ampliamente generalizada en el territorio se volcaba no sólo en la agricultura, sino también en las obras públicas. En esta fase la especialización edilicia resuelve brillantemente el problema de la canalización del gasto público en el Sur y alimenta el crecimiento de una burguesía local que, entre municipio y ministerio, libre de todo control, administra un tumultuoso desarrollo urbano y llega a controlar el flujo de fuerza de trabajo urbanizada. En resumen, la especulación en las áreas urbanas permite un nexo ventajoso entre la clase política y nuevos sectores empresariales; aquélla, a cambio de ventajas económicas (participación en las utilidades) mantiene a la construcción libre de intervenciones de control político-administrativos. ${ }^{14}$

Únicamente en la segunda década, y en particular a partir de 1957, con el comienzo de la fase de industrialización selectiva que concede incentivos a la industria privada y establece nuevas líneas de intervención para la industria pública, el marco económico del Mezzogiomo, y en particular en las áreas centrales, implica cambios en el seno del bloque de poder y en la composición de clase. Nos hallamos entonces ante la crisis del antiguo aparato de poder político-clientelar y a su sustitución por un nuevo aparato, más poderoso y estrechamente entrelazado con los entes de Estado. La intervención de las participaciones estatales y de la empresa pública en general se traduce en grandes implantaciones de producción básica y en una

13. Sobre este tema, véase A. Graziani: «EI Mezzogiono nell'econornia italiana oggin, Incbiesta, 29 (1977), op. cit. Véase también A. Bagnasco, Le tre Italie (Bolonia: Il Mulino, 1977). P. Ceccarelli, «Impressa pubblica e intervento territoriale», en AAVV, Sviluppo e sottosviluppo nel Mezzogiorno d'Italia (Nápoles: Morano, 1972).

14. C. Donolo, «Sviluppo ineguale e disgregazione sociale nel Meridione», Quaderni Piacentini, 47 (1972). Del mismo autor, kMutamenti nel blocco sociale dominante del Mezzogionon (en prensa) en Einaudi, en el volumen colectivo que contiene las actas del Encuentro del CENDES sobre la Italia después de 1968. 
alta intensidad del capital prácticamente sin efectos inducidos y con escasa capacidad ocupacional, cuya localización sólo excepcionalmente coincide con los grandes centros urbanos meridionales.

Las llamadas catedrales en el desierto se crean afuera de las ciudades, las cuales ven su tejido social cada vez más terciarizado. Al menos a partir de 1968, no se trata tanto de falta de industrialización del Mezzogionno como de falta de desarrollo del empleo. Las inversiones industriales, en miles de millones de liras, pasaron de 343,8 en 1961 a 623,3 en 1968 y a 2.591 en 1973, y su incidencia sobre el total de las inversiones pasó del $14,4 \%$ en 1961 , al $26,3 \%$ en 1968 , y al $43,2 \%$ en 1973 . Sin embargo, no asistimos a un desarrollo correspondiente del empleo; el excedente de fuerza de trabajo trobanizada sólo encuentra ante sí posibilidades terciarias que disimulan la subutilización y el parasitismo. En efecto, a la progresiva pérdida de importancia de la agricultura y a las modificaciones de la estructura industrial corresponde, por ello, un destacado proceso de terciarización. El porcentaje de renta de la administración pública pasa del $12,8 \%$ en 1951 , al $14,6 \%$ en 1961 , y al $16,3 \%$ en 1973 , mientras que la incidencia de los ocupados en el sector salta del $5,8 \%$ ał $11,2 \%$ entre 1951 y 1973.

Al menos a partir de 1968 , no hay que atribuir la terciarización del tejido social meridional, que a menudo enmascara procesos de subutilización de la fuerza de trabajo y de parasitismo, a falta de industrialización, sino a falta de desarrollo del empleo. No se trata de un proceso exclusivo del Mezzogiorno, aunque aquí se presenta con rasgos más acusados, sino que se inserta en un contexto en el que las otras actividades están menos de. sarrolladas. Es decir, que se observa la consolidación de aquel proceso de inflación del aparato buroctático que ya se había iniciado durante el fascismo, y que tesponde a la doble necesidad de contener las tensiones sociales y de procurar una base de consenso entre los pequeños buróctatas que de esta manera se pueden agregar al bloque dominante. El proceso de terciarización se plantea, por ello, como típico del contexto meridional. En efecto, no estamos frente a una realidad industrial que en su fase más avanzada expanda los sectores cometciales, de dirección, etc., como en el Norte, sino más bien ante un proceso de degradación, ante un terciario de baja calidad cuya función no es suministrar servicios o satisfacer necesidades sociales, sino dar empleo a la fuerza de trabajo.

Se ha dicho que se trata de una terciatización de sobtevivencia, ${ }^{15}$ de disgregación, de clientelismo, que bajo el control de la lamada burguesía de Estado se resuelve en una serie de subsidios directos e indirectos. Así

15. A. Collidà, op. cit. 
se echa a andar lo que se definiera como «proceso de monetización del subdesarrollo», pues en buena medida el precio que paga el régimen democristiano para mantener los equilibrios sociales se traduce en política de subsidio. Esto es todo lo que hace falta para controlar al menos en parte las tensiones del mercado de trabajo y para sustituir precisas relaciones de clase por relaciones más mediatizadas: ya no se trata de "patrón y obrero", sino de «autoridad y marginal». ${ }^{16}$ La lógica clientelar permite fácilmente rescatar gente para el sistema; en efecto, todo receptor de subsidios se siente un favorito, busca soluciones individuales y como le es difícil distinguir contrapartes precisas en el conjunto indiferenciado de figuras sociales, «no lucha contra el Estado, sino junto al Estado» para que adecue el thujo de los recursos transferidos.

Predominio de la asistencia y de la mediación sobre la producción; parasitismo y terciarización hipertrófica; papel creciente del Estado; en este contexto ya no es fundamental el control clásico de los medios de producción, sino que lo importante es más bien el acceso políticamente protegido a los recursos públicos. Y las mismas relaciones de producción en el Mezzogiorno se resuelven a menudo en «telaciones de división de las transferencias». Pero en esta altura hay que analizar cuál es el grado de funcionalidad capitalista de la intervención del Estado en el momento en que sus dificultades para incrementar las características de asistencia se vuelvan cada vez mayores. Ni es tampoco suficiente plantear la exigencia de un proceso de terciarización «cualificada» si el nudo de la cuestión sigue siendo la inadecuada base productiva. Quitar peligrosidad a la intervención pública en el Sur, que ya no se considera como una alternativa a las vocaciones empresariales privadas, y tender a programas renovados de obras públicas, puede significar una vez más tener como objetivo la reagrupación de determinadas capas, precisamente las que proliferan con sólidas garantías a la sombra de la mediación política. Se trata del mecanismo por el cual el Estado se promueve a sí mismo y promueve a sus agentes, expandiendo con su intervención las capas que de él dependen.

\section{Las clases subalternas y los mecanismos de control social}

La modificación de las telaciones ciudad campo, el crecimiento de la ciudad, el papel cada vez más determinante de la intervención pública y la función decisiva de la actividad terciaria que babíamos visto en el párrafo

16. N. Ginatempo, La città del Sud: Territorio e slassi sociali (Milán: Mazzota, 1976); también la introducción de E. Mingione. 
anterior, constituyen una de las caras del proceso de transformación social. Este proceso afectó sobre todo a las regiones meridionales y encuentra su principal expresión, por una parte, en el nivel de composición de clase y en la emergencia y consolidación de la burguesía de Estado, y por otta parte, en el progresivo ascenso de las capas agrícolas. Se trata de una declinación que afecta a todas las clases rurales en la medida en que afecta a la actividad agrícola. En la actualidad, probablemente el desplazamiento del eje del poder político-económico hacia la ciudad sea el elemento clave de los nuevos términos de la cuestión meridional.

Precisamente por esto vale la pena entrar más específicamente en la esencia de la estructura de clase del Mezzogiorno partiendo de la burguesía de Estado y analizando su compleja articulación y la diferente colocación de sus miembros en el seno de la estructura de poder. En el citado ensayo de Castronovo, este autor observa que ya durante el fascismo «la inflación de los cuadros de la burocracia estatal y paraestatal, la enorme cantidad de ex combatientes en la administración [...], así como de pequeños buró. cratas en los entes corporativos, sirvieron para consolidar la influencia de la pequeña burguesía y de la burguesía media, para darles la ilusión de participar de modo masivo en la gestión del poder». Por otra parte, se afirmó una nueva «aristocracia burocrática» constituida por comis di stato, por personal directo de los ministerios, por dirigentes de partido, de entes paraestatales y de servicios públicos con privilegios corporativos propios, inserta en una vasta realidad clientelar, de dosificación y de asesoramiento de las intervenciones en materia de trabajo, de obras públicas, de gestión de las instituciones judiciales y de policía, de organización del consenso. ${ }^{7}$

El primero de los dos componentes gozaría de la ilusión de participar en el poder, el segundo, del poder efectivo. Es esta profunda diferencia la que implica una articulación del análisis en relación a lo que hemos Ilamado «burguesía de Estado». Lo primero que hay que precisar al respecto es que el término ya ha perdido valor en el uso y abarca tanto sectores de la gran burguesía como sectores de la pequeña burguesía, y que en consecuencia puede prestarse a equívocos si no se procede a una posterior clatificación. La desagregación se lleva a cabo de una manera articulada y llega incluso al seno de los estratos subalternos. Poco ayuda a la comprensión de la actual situación social del Mezzogiorno hablar de la existencia de «una vasta capa burocrática parasitaria». Por cierto que el mecanismo que ha llevado a la inflación del empleo en el sector público es único, pero no obstante ello, ha colocado los diversos estratos sociales de un modo muy diferenciado en el seno de la estructura de poder burocrático administra-

17. V. Castronovo, op. cit., p. 328. 
tivo. Por lo tanto, hay que subrayar la profunda diferencia de condición social entre personas que a menudo reingresan en los mismos agrupamientos estadísticos porque se ocupan con la misma condición profesional en sitios de trabajo similates. Por cierto que el gozar, aun de manera muy diferenciada, de privilegios y sinecuras que tienen su origen en la misma fuente, puede atar al mismo carro corporativo a quienes dependen de una misma institución. Es justamente en este mecanismo en el que se basa el poder de la burocracia y su capacidad para hacer aceptar formas esencialmente jetárquico-corporativas destinadas a garantizar la estabilidad políticosocial del sistema, haciendo prevalecer el principio de la autoridad. ${ }^{18}$

Para nosotros es éste el problema centrai -es decir, el de la base de consenso que Ia inflación del aparato burocrático determina - para comprender la función de estos estratos en la sociedad y en la economía italianas. En el aparato del Estado (que incluye entes paraestatales, entes públicos, entes locales, etc.) encontramos tanto categorías que por connotación socio-económica se homologan al projetatiado (ujieres), como pequeña y gran burguesía (ditectores y consejeros de administraciones de diversos entes, jefes de organismos de asesoramiento regionales y municipales de las grandes ciudades). Por tanto, la posición de éstos debe analizarse de un modo articulado en el interior del bloque de poder al que nos hemos referido en la introducción. Si es cierto que los estratos subalternos consiguen acceder a ciertos pequeños privilegios corporativos, los estratos superiores son los que acaparan los grandes privilegios. Son ellos los que mantienen en sus manos la gestión de los puestos de trabajo, la gestión del crédito agrario e industrial, la gestión de los fondos de previsión y pensiones, la gestión del gasto público, sea para obras productivas o no. Y de estas fuentes, es decir, de la posesión en sus manos de las riendas del gasto público es de donde el estrato superior de la burguesía de Estado extrae su poder y lo consolida. Esta burguesía, además, extrae poder de su dominio clientelar de la base del aparato burocrático administrativo del Estado.

Con el crecimiento de la intervención pública crece, se diferencia y se articula en su interior la burguesía de Estado. Pero es imposible comprender el papel que ella desempeña si sólo se alude a este aspecto. Hay que preguntarse el porqué de la expansión de esta burguesía -así como la con.

18. Al respecto es de fundamental utilidad el libro de S. Caruso, Burocrazia e capitale in Italic (Venecia: Bertani, 1974), que muestra al mismo tiempo la importancia de la jerarquía y de la ideología de la desigualdad y su reciente crisis provocada por la propia extensión del aparato burocrático. En lo que hace al papel de estos estratos desde el punto de vista económico, Caruso ( $\mathrm{V}$ V. Parlatio en la introducción al volu. men), ponen de relieve su contribución al aumento de la demanda interna sobre todo de bienes de consuro no social. 
temporánea expansión de grupos de trabajadores improductivos que no pertenecen a la burguesía. La respuesta ha de buscarse en el mecanismo general de acumulación que caracterizó Italia. Ya hemos visto cómo en el Mezzogiorno, en particular, el crecimiento de una industria de base que no incrementa el empleo, junto con el acusado éxodo del campo, determinaron una grave expulsión del sistema productivo de fuerzas de trabajo que se ha tratado de absorber en el sector terciario (administración pública) con el doble objetivo de contener las tensiones sociales y procuratse una base de consenso entre los pequeños burócratas. Eso es lo que explica el crecimiento del aparato del Estado, y en ello se expresa la precisa voluntad de las fuerzas políticas dominantes de determinar una modiffcación en la estructura social del Mezzogiorno con el desartollo numético de estratos que se van agregando al bloque dominante.

El mecanismo de desarrollo no gazantiza, pues, la absorción de fuerza de trabajo, sino que más bien favorece su expulsión; pero el resultado de este proceso - lejos de expresarse como una contradicción- es funcional para las necesidades de estabilidad político-social del sistema. Las fuerzas de trabajo, expulsadas como consecuencia de la restricción de la base productiva y de la reestructuración, son reabsorbidas en ocupaciones improductivas. Favorecidos con un empleo cuyo carácter improductivo son los primeros en teconocer, los dependientes de los aparatos públicos se convierten en base importante de consenso. Favorecidos (con el puesto de trabajo y los privilegios al mismo conexos) por los estratos dominantes, ocupan por ello mismo una posición subalterna en una estructura de poder cuyos sujetos principales los utilizan como masa de maniobra y aparato clientelar; pero al mismo tiempo son también ellos sujetos activos de la gestión en la periferia del poder propiamente dicho, en la medida en que, en el nivel local, pueder ejercer control sobre otros estratos subaiternos.

Estas áltimas consideraciones introducen el discurso acerca de las clases subalternas. Su modificación es el reverso de un proceso de desarrollo económico que no se ha producido de modo uniforme en todo el país, y que, por tanto, refleja el papel que desempeña el Mezzogiorno en el desarrollo económico nacional. En términos de las clases sociales en el Mezzogiorno, este proceso ha asistido a: 1) La crisis drástica de las capas medias tradicionales y la proletarización de las capas attesanales y de los campesinos. Este proceso de proletarización entra de lleno en un esquema dicotómico de análisis de las clases sociales que distingue, por una parte, concentración capitalista, y por otra parte, «privación de los medios de producción» de las pequeñas capas medias. 2) La emergencia de una nueva categoría de proletarios como consecuencia de los procesos arriba descritos. 3) La emergencia de nuevos estratos — siempre como consecuencia del 
proceso ya mencionado-- cuya transformación en clase obreta no se realiza, ya sea por motivos de orden social, ya sea de orden económico.

A quien considera los otros aspectos del problema (la emergencia incluso en el Mezzogiomo de una clase obrera de nuevo tipo, la consolidación de un proletariado de la construcción, y para quien se acupa de agricultura, un redimensionamiento y al mismo tiempo una reestructuración del proletariado rural) remitimos a un estudio más detallado sobre cambios en la estructura social del Mezzogionno. ${ }^{19}$ Aquí nos limitaremos a analizar sólo algunos aspectos relativos al tercer punto, y en la práctica al incremento de la población subsidiada por el incremento de trabajadores adheridos al terciario (administración pública y servicios, además del comercio). En este conjunto, sobre todo en el interior de los empleados públicos, es donde hay que buscar el componente más significativo de la pequeña burguesía meridional. Es justamente la expansión de esta categoría la que explica diversos fenómenos politico-sindicales en el Mezzogiono.

Tanto la expansión de los pertenecientes al terciario como el crecimiento de la población subsidiada son expresiones diversas de un proceso único, cual es la ocupación de trabajadores supernumerarios y su absorción en el proceso productivo. Pero su influencia en los respectivos contextos territoriales es diversa. El primero es más propio de la ciudad, mientras que el segundo predomina en el campo. Además, el primero crea posiciones profesionales precisas, determinando una modificación notable en la estructura de clase. En efecto, el complejo mecanismo de desarrollo capitalista recupera en condición social no proletaria sujetos de extracción proletaria - más a menudo campesina y pequeño-burguesa (artesanos, etc.) colocándolos en actividades no productivas $y / o$ sin utilidad social.

Son varios los atutores que ven en estos nuevos estratos las capas medias propias de esta fase del desarrollo económico. Mucho se puede discutir acerca de la situación de clase de éstos; sin embargo, hay que subrayar la relativa novedad de su expansión. No se trata, como tradicionalmente to ha entendido la literatura, de «capas medias» formadas por trabajadores independientes generalmente poseedores de medios de producción, artesanos y campesinos, etc., sino predominantemente por trabajadores del aparato buroctático-administrativo. Las capas «en declinación» de las que habla $\mathrm{S}$. Berger cuando analiza el uso político de las mismas, ${ }^{20}$ son otras. Éstas están eventualmente en ascenso.

19. E. Pugliese, «Evoluzione delia struttura di classe nel Mezzogionno», en AAVV, Investimenti $e$ disoccupazione indotta nel Mezzogiorno (II Mulino, en prensa).

20. S. Berger, «Uso politico e soprawivenza dei ceti in declino», en AAVV. Il caso italiano, a cargo de Cavazza-Grabard, Garzanti (Milán, 1974). 
En tealidad, en referencia a la pequeña burguesía meridional hay que destacar vigorosamente que su estructura interna ha cambiado drástica. mente y que también ha cambiado drásticamente la importancia de los divetsos estratos que la componen. Campesinos medios y artesanos, por una parte, pequeña burguesía empleada, por otra, eran los componentes a los que se dirigía el partido que mayor hegemonía ha tenido sobre las capas medias, la DC.

La capacidad de hegemonía en el campo, garantizada también y sobre todo por la organización colateral en el campo, la «Coldiretti», se realizaba a tzavés de la alusión a la ideología corporativista propia de las capas no proletarias. Sobre esta misma base se regía la hegemonía sobre otras categorías que, aunque menos significativas en el plano político y sindical, tenían una notable importancia en el Sur, las categotías artesanales.

Pero estas categorías no proletarias, justamente dadas las transformaciones que han tenido lugar en la estructura económica y social, son menos importantes. En lo que toca a los campesinos - ya sea por el éxodo y la proletarización, ya sea por otros motivos--, se advierte entre ellos, con toda seguridad, menos «tensión corporativa», por así decirlo. Nótese, entre otras cosas, que este fenómeno ha sido muy bien comprendido por la organización corporativa del campo, la «Coldiretti», que en amplias áreas meridionales se presenta cada vez menos con el rostro de quien quiere «todos propietarios y no todos proletarios», y se dispone a desempeñar el papel de gran limosnera, distribuidora de una asistencia volcada cada vez menos a la propiedad y cada vez más al campesino, como persona, como inválido o pensionado. En realidad, si bien no ha habido proletarización en sentido específico de vastas masas campesinas, los que no se han proletarizado continúan en gran medida su existencia en condiciones de pobreza, mantenidos por subsidios y por remesas de familiares emigrados.

En lo que se refiere a la otra componente pequeño-butguesa, los artesanos, con las modificaciones de las estructuras del asentamiento, los grandes procesos de urbanización, la marginación de áreas de colina y montaña, ha tomado su base demográfico-social del asentamiento. Por otro lado, en lo que concierne al artesanado de producción, de tipo más tradicional, se ha visto por completo penetrado, aun en las regiones más recónditas del Mezzogiorno, por el metcado de los productos de la industria capitalista moderna.

En consecuencia, ha sido la evolución del sistema capitalista nacional lo que ha hundido a la pequeña burguesía productiva. Vale la pena dedicar unas palabras a mostrar la declinación de las capas medias tradicionales y el surgimiento de la «nueva capa media». 
En el capítulo 23 de El Capital, titulado «La ley general de la acumulación capitalista», Marx hace notar que «al producir la acumulación del capital, la población obrera produce también, en proporciones cada vez mayores, los medios para su propio exceso relativo. Es ésta una ley de población peculiar dél régimen de producción capitalistas." Esto quiere decir que la producción de sobreproducción relativa, de «exceso de proletarios», es un dato inherente al desarrollo capitalista. Lo que caracteriza el modelo de desarrollo de un determinado sistema económico-social moderno es su modo variado de manifestarse, pero sobre todo, para lo que nos concierne, su transformación y reabsorción en formas particulares destinadas a no ingresar en el ejército obrero activo, $y$, por tanto, a no expresar por completo su naturaleza proletaria.

Los taecanismos de inflación del terciario han de referirse también a esta función. Pero tal vez si se articula el discurso se puede distinguir entre componentes diversos. Por ejemplo, en lo que concietne al pequeño cometcio minorista, de muchas maneras se ha puesto en evidencia que muchos de los elementos que le pertenecen constituyen un nuevo modo de expresarse de la superpoblación relativa latente que tradicionalmente era absorbida por la agricultura. ${ }^{22}$ Se trata de trabajadores a menudo independientes o colaboradores, «dispuestos a entrar a formar parte del proletariado de la manufactura», es decir, que están en disponibilidad para una ocupación incluso de carácter proletario en la industria siempre que se diera la oportunidad de ello.

Pero la ampliación del terciario público -en particular los empleos en la administración pública- expresa también la modificación de clase de los sectores de la superpoblación relativa y su transferencia de la condición proletaria de hecho (que es la de todo componente de la super. población relativa), a una condición particular que, por cierto, no puede definirse automáticamente como pequeñoburguesa, pero que tampoco se caracteriza ya por un estado socio-económico obrero. El mismo Marx, en múltiples ocasiones, puso ya suficientemente en evidencia este proceso de transformación de una masa proletaria en número excesivo en un estrato de empleados. ${ }^{23}$ Su gravitación en los sistemas capitalistas mismos es más

21. K. Marx, El Capital, vol. I, cap. XXIII (México: Fondo de Cuitura Económica, 1968), 5a. ed., p. 534.

22. Este tipo de modificación de la composición de la SPR ya ha sido puesto en evidencia por algunos autores. Entre otros, por M. Paci, Mercato del lavoro e classi sociali, op. cit., distingue como componente de la SPR a los jóvenes escolarizados (diplomados) que desartollan actividades precarias.

23. En las luchas de clase en Francia, por ejemplo, Marx observa que el desarrollo de los trabajadotes improductivos, como consecuencia del gasto público, se 
o menos relevante. En Italia es muy notable y se localiza en particular en el Mezzogiorno, Io que caracteriza la estructura social de la ciudad y acentúa el carácter parasitario de la misma. Es estimulante la consideración de A. Collidà cuando habla de estos trabajadores y dice que «si bien parece correcto poder hablar de subproletariado en referencia a la ciudad meridional, dicho subproletatiado no está representado por los miles y miles de trabajadores precarios que se esfuetzan de todas las maneras para hallar medios de sostenimiento, sino por los miles de reclutados en el empleo público, que no tienen tareas precisas, son marcadamente subutilizados [...] y tienen un salario mensual estable» ${ }^{24}$ Sólo puede compartirse este juicio de A. Collida si se tiene presente el carácter polémico y el papel político que muy a menudo estos estratos han terminado por obtener. Pero no parece absolutamente correcto, en cambio, usar el término subproletariado en el plano analítico.

Hay que decir que esta nueva capa de consenso no tiene tampoco la función de la pequeña burguesía tradicional meridional que Gramsci iluminara con sus análisis. Justamente en tanto urbanizada, no puede desempeñar el papel de bisagra tespecto de los estratos subalternos de los campesinos. La pequeña burguesía púbilica, o mejor, las capas de empleados de las dependencias de los entes públicos o parapúblicos, representan sobre todo en la ciudad meridional una de las tantas componentes particulares en las que se expresan las capas subalternas incapaces de hallar un momento de inclusión.

Pero a esta altura se impone una consideración más. Ante todo, habría que analizar más detalladamente la composición de clase de los funcionarios públicos. Vale preguntarse a qué clase pertenecen los «reclutados del empleo público", los subproletarios de los que babla Ada Collidà. Si los une la ideología corporativista, también es cierto que el respectivo comportamiento social y político es muy diferente, lo que depende de varios factores, entre los cuales es importante la historia político-sindical del contexto en el que se encuentran. En otros términos, si el particularismo pequeñoburgués del Mezzogiorno trasciende los límites de la pequeña burguesía y el corporativismo se vuelve el elemento de mayor preocupación respecto de la vida político-sindical de la ciudad, también es cierto que en algunas cir-

debe a que la burguesía «opone una parte de los proletarios a otra», ya que ella no Ileva «la' camisa del obrero». Y en El 18 Brumaria se vincula Ia expansión de la burocracia al proceso de creación de un exceso de fuerza de trabajo, puesto que ésta busca empleo en el Estado y provoca ja formación de aquéflia. Véase K. Marx, El 18 Brthmario de Luis Bonaparte y Las lucbas de clase en Francia, passim.

24. A. Collidà, «La città meridionale», op. cit, Pp. 60-62. 
cunstancias (como es el caso de Nápoles en 1975-1976), estos mismos estratos logran liberarse y participar en un proceso de renovación que tiene como primer protagonista a la clase obreta, el proletatiado industrial. Es cierto que este fenómeno del aumento del empleo público no es sólo un hecho urbano, pero, como es obvio, interesa particularmente a las ciudades, ya que es en la ciudad donde se concentran las estructuras institucionales y las oficinas que absorben a estos trabajadores. No obstante, estos incrementos de ocupación estable, más o menos bien retribuida, no son capaces, como hemos visto, de llevar las tasas de actividad a niveles decentes.

En el campo las tasas de actividad no son más elevadas, pero al nivel de empleo hay que unir la característica de éste. Por un lado, la precariedad ocupacional, y por otro lado, la multiplicidad de rentas más o menos modestas provenientes de diversas fuentes, son las características de la familia rutal taetidional. Puesto que los distintos conceptos del ingreso, la renta que percibe cada miembro de la familia, corresponden a diversas condi. ciones sociales (campesino, pensionado, receptor de remesas, obrero de la construcción, etc.), la situación de clase de muchos núcleos familiares es extremadamente compleja. Esto vale para todas las áreas agrícolas, pero en las más pobres, en las zonas del interior, los réditos derivados de subsidios y pensiones adquieren una importancia particular. Cabezas de familia, cultivadores directos, «inválidos» o cuarentones en perfecto estado de salud, arrendatarios de pequeñísimas propiedades que no darían para vivir ni siquiera un mes, administran una renta familiar cuyo principal componente es el que proviene de las pensiones; es así como encontramos farmilias que como campesinas se clasificarían como campesinos pobres, pero cuyo nivel de vida está muy por encima del de éstos. Y el análisis de clase vuelve a complicarse si se considera el modo en que esta renta se produce, si se considera cuál es la posición de los receptores de subsidios y de pensiones en las relaciones de producción.

A menudo estos casos son representativos de la realidad de las clases subalternas en las áreas rurales internas del Mezzogiorno. Es evidente que ya no es la tierra la base estructural del poder. En efecto, la gestión en escala local de las migajas del gasto público ha tomado su Lugar. Pero este proceso se ha visto acompañado de una limitación relativa de la influencia social de todas las clases que se localizan territorialmente en estas âreas, respecto de las cuales se puede hablar de subordinación y marginación generales. En resumen, es verdad que no sólo los campesinos pobres y los proletarios de estas zonas están particularmente marginados -es decir, que tienen escasa capacidad para incidir en las opciones que les conciemen, para controlar su suerte-, sino que la totalidad del poder de conjunto 
que se cuenta en estas áreas -en comparación al resto del Mezzogiorno y al sistema socio-económico nacional- es más modesta. Para los mecanismos de consenso electoral, estas zonas y la inmensa base de población subsidiada que en ellas residen, revisten una enorme importancia, pero su función no trasciende demasiado este nivel. ${ }^{25}$

El desplazaniento del eje político a la ciudad, a la sede física de las instituciones, es mucho más marcado que en ningún momento anterior del Mezzogiorno. Si la actividad terciaria es la dominante, si la gestión deI gasto público y la administración del Estado son la base de la economía, es comprensible que la «cuestión meridional» vaya dejando de ser una cuestión agraria para convertirse cada vez más decididamente en «cuestión urbana».

Gabriella Pinnako

Istituto di Sociologia

Facoltà di Lettere

Università degli Studi di Salerno

Via Irno

Salerno

Italia

25. Ei problema de la marginación y de la pérdida de pođer también se hace sentir en otros estratos sociales; pensemos, por ejemplo, en la pequeña burguesía enpleada, que, respecto de la capacidad y de la función de opresión social y económica del proletariado que una vez había tenido, ve su poder a nivel local extremadamente zedimensionado. Es interesante recordar una polémica que tuvo lugar en los comienzos de la década de 1960 entre Wright Mills y Parsons acerca de la cuestión de la «sumacero" del poder. Wright Mills sostenía que la sumatoria de las relaciones de poder es siempre cero, es decir, que "o cuento más yo o cuentas más tú». Parsons, en cambio, sostenía lo contratio, a saber, que la sociedad progresaba en articulación, que se crea. ban nuevas funciones, nuevos espacios $y$, por tanco, aumentaba la cantidad total de poder de gestión y, como es evidente, había más poder para todos. En realidad, esta segunda interpretación, que en términos de clase no es correcta, puede utilizarse, sin embargo, en el nivel del análisis territorial. T. Parsons, «On the concept of political power», Class, Status and Power. a cargo de R. Bendix y S. M. Lipset (Nueva York: Free Press, 1966). 